\title{
Criptógamos do Parque Estadual das Fontes do Ipiranga, São Paulo, SP. Algae, 42: Bacillariophyceae (Surirellales)
}

\author{
Krysna Stephanny de Morais Ferreira ${ }^{1}$ e Carlos Eduardo de Mattos Bicudo ${ }^{2,3}$
}

Recebido: 4.05.2016; aceito: 8.12.2016

\begin{abstract}
Cryptogams of the Parque Estadual das Fontes do Ipiranga, São Paulo, SP. Algae, 42: Bacillariophyceae (Surirellales)). Floristic survey of order Surirellales (Bacillariophyceae) in the Parque Estadual das Fontes do Ipiranga (PEFI), São Paulo, SP, Brazil was based on the analysis of 28 sampling units. Plankton samples were collected with a plankton net and periphyton by scraping hard substrates and/or gathering aquatic macrophytes. Samples were oxidized and analyzed under a light microscope. Two genera and 15 species were identified. Nine taxa are cited for the first time for the PEFI area: Stenopterobia delicatissima (F.W. Lewis) L.A. Brébisson ex H. van Heurck, S. pelagica F. Hustedt, S. planctonica D. Metzeltin \& H. Lange-Bertalot, S. curvula (W. Smith) K. Kramer, Surirella angusta F.T. Kützing, S. guatimalensis C.G. Ehrenberg, S. stalagma M.H. Hohn \& J. Hellerman, S. splendida (C.G. Ehrenberg) F.T. Kützing and S. tenera W. Gregory. Keywords: diatoms, floristic survey, periphyton, phytoplankton
\end{abstract}

RESUMO - (Criptógamos do Parque Estadual das Fontes do Ipiranga, São Paulo, SP. Algae, 42: Bacillariophyceae (Surirellales)). O levantamento florístico das Surirellales (Bacillariophyceae) do PEFI, Parque Estadual das Fontes do Ipiranga, São Paulo, SP, Brasil resultou da análise de 28 unidades amostrais. As amostras planctônicas foram coletadas com auxílio de rede de plâncton e as de perifíton pela raspagem de substratos duros ou coleta de macrófitas aquáticas submersas. O material foi oxidado e analisado aos microscópios de luz. Dois gêneros e 15 espécies foram identificados, dos quais nove são novas citações para o PEFI e são: Stenopterobia delicatissima (F.W. Lewis) L.A. Brébisson ex H. van Heurck, $S$. pelagica F. Hustedt, S. planctonica D. Metzeltin \& H. Lange-Bertalot, S. curvula (W. Smith) K. Kramer, Surirella angusta F.T. Kützing, S. guatimalensis C.G. Ehrenberg, S. stalagma M.H. Hohn \& J. Hellerman, S. splendida (C.G. Ehrenberg) F.T. Kützing e S. tenera W. Gregory.

Palavras-chave: diatomácea, fitoplâncton, levantamento florístico, perifíton

\section{Introdução}

A Ordem Surirellales está constituída por três famílias e nove gêneros segundo Mann in Round et al. (1990). A primeira, Surirellaceae, compreende grande parte dos gêneros da ordem, como segue: Surirella P.J.F. Turpin 1828, Campylodiscus C.G. Ehrenberg ex F.T. Kützing 1844, Cymatopleura W. Smith 1851, Plagiodiscus A. Grunow \& T. Eulenstein 1867, Hydrosilicon J. Brun 1891, Stenopterobia L.A. Brébisson \& H. van Heurck 1896 e Petrodictyon D.G. Mann 1990. As famílias Entomoneidaceae e Auriculaceae são constituídas apenas por um gênero cada uma que são, respectivamente, Entomoneis C.G. Ehrenberg 1845 e Auricula F. Castracane 1873.

Surirellales são as diatomáceas que possuem o sistema de rafe erguido por pontes de sílica sustentadas pelas chamadas fíbulas, que variam de forma e tamanho conforme a família (Round et al. 1990, Ruck 2010). A presença de uma rafe quilhada tem como principal função favorecer a maior motilidade em substratos com pequenas escalas de irregularidade, tais como sedimentos finos e lodosos (Round 1990, Ruck \& Theriot 2011).

Os gêneros que compõem a ordem podem ser encontrados habitando uma variedade de sistemas de água doce, incluindo lagos, rios e pântanos (Stevenson et al. 1996). Alguns são exclusivamente estuarinos e marinhos, como Auricula, Petrodictyon e Hydrosylicon. Os gêneros Campylodiscus, Surirella, Entomoeoneis e Cymatopleura podem ser encontrados nos sedimentos de lagos profundos (Lowe 2003), enquanto que outros são restritos às águas com baixo

1. Instituto de Botânica, Programa de Pós-graduação em Biodiversidade Vegetal e Meio Ambiente, São Paulo, SP, Brasil

2. Instituto de Botânica, Núcleo de Pesquisa em Ecologia, Av. Miguel Estéfano, nº 3681, 04301-902 São Paulo, SP, Brasil

3. Autor para correspondência: cbicudo@terra.com.br 
$\mathrm{pH}$, como é o caso de Stenopterobia (Round et al. 1990).

Para o Brasil, os trabalhos que mais citam e melhor ilustram as espécies estão concentrados na região Sul do país (Rodrigues 1984, Torgan 1985, Shirata \& Moreira 1987, Laudares-Silva 1987, Flôres et al. 1999, Fernandes et al. 1990, Mosimann et al. 2001, Burliga et al. 2005, Fernandes 2006, Raupp et al. 2006, Torgan \& Weber 2008, Silva et al. 2010, Laux \& Torgan 2011, Santos et al. 2011, Bartozeck et al. 2013, Rosa \& Garcia 2014) sendo poucos os publicados para as demais regiões (Azevedo \& Cutrim 1993, Souza-Mosimann 1997, Dias-Castro et al. 2003, Santiago-Hussein \& Oliveira 2005, Aprile \& Meira 2007, Oliveira et al. 2012, Menezes \& Domingos 1994).

Em trabalhos sobre o conhecimento da flora ficológica do Estado de São Paulo, alguns autores registraram a ocorrência de representantes de Surirellales. São eles: Bicudo et al. 1993, Magrin \& Senna 1997, Magrin 1998, Magrin \& Senna 2000, Graça et al. 2007, Moutinho et al. 2007, Bicudo et al. 2009 e Almeida \& Bicudo 2004.

Para o Parque Estadual das Fontes do Ipiranga (PEFI), o conhecimento da diversidade das Bacillariophyceae pode ser encontrado nos trabalhos de Tavares (2001), Morandi (2002, 2008), Carneiro (2003, 2007), Rocha \& Bicudo (2008) e Marquadt $\&$ Bicudo (2014). Especificamente para a ordem Surirellales, as únicas contribuições constam em trabalhos de cunho ecológico (ex. Fonseca et al. 2014) e em trabalhos não publicados como dissertações de mestrado e teses de doutorado (Lopes 1999, Ferragut 2004, Costa 2008) que, na maioria das vezes, não ilustraram o material identificado.
O objetivo do presente trabalho foi conhecer a diversidade taxonômica e a variabilidade populacional das Surirellales do Parque Estadual das Fontes do Ipiranga.

\section{Material e métodos}

O PEFI (Marquadt \& Bicudo 2006, figura 1) está situado no sudeste do Município de São Paulo e foi criado em 1893, com finalidade de proteger a fauna e a flora da bacia do riacho Ipiranga (São Paulo 1991). Com ca. 526,38 ha e localizado na bacia do Alto Tiete (Santos \& Funari 2002) o PEFI comporta 10 sub-bacias hidrográficas, as quais abastecem nove reservatórios artificiais localmente chamados lagos (tabela 1) (Fernandes et al. 2002). A vegetação do Parque é classificada como ombrófila densa, situada no planalto de domínio da Mata Atlântica que reúne diversas outras formações florestais dos tipos Floresta Ombrófila Densa, Floresta Ombrófila Aberta, Floresta Ombrófila Mista e Floresta Decidual (Veloso \& GoesFilho 1892), além de incluir algumas espécies de Floresta Estacional Semidecídua e de Cerrado (Nastri et al. 1992). O PEFI encontra-se na região de contato entre rochas pré-cambrianas e sedimentos da Bacia Sedimentar (Fernandes et al. 2002).

Para a presente pesquisa foram analisadas 28 unidades amostrais provenientes do acervo do Herbário Científico do Estado "Maria Eneyda P. Kauffmann Fidalgo" (SP) do Instituto de Botânica da Secretaria do Meio Ambiente do Estado de São Paulo. O material planctônico foi coletado com rede de plâncton confeccionada com tecido de náilon de abertura de malha de $20 \mu \mathrm{m}$. Quanto ao material perifítico, as amostras foram recolhidas a partir de exemplares inteiros ou de partes submersas

Tabela 1. Localização dos sítios de coleta de Surirellales, Parque Estadual das Fontes do Ipiranga, São Paulo, SP, Brasil.

Table 1. Location of Surirellales sampling sites, Parque Estadual da Fontes do Ipiranga, São Paulo, São Paulo State, Brazil.

\begin{tabular}{lccc}
\hline Local de coleta & Data & Latitude & Longitude \\
\hline Lago das Ninfeias & $18-$ VII-1991 & $23^{\circ} 38^{\prime} 18,9^{\prime \prime}$ & $46^{\circ} 37^{\prime} 16,3^{\prime \prime}$ \\
Lago do Centro de Ciência e Tecnologia & $7-$ XI-1996 & $23^{\circ} 39^{\prime} 03,4^{\prime \prime}$ & \\
Lago dos Bugios & $15-$-I-1997 & $23^{\circ} 30^{\prime} 19,3^{\prime \prime}$ & $46^{\circ} 37^{\prime} 16,3^{\prime \prime}$ \\
Lago do Monjolo & $7-X I-1996$ & $23^{\circ} 38^{\prime} 26^{\prime \prime}$ & $46^{\circ} 37^{\prime} 10,3^{\prime \prime}$ \\
Córrego Pirarungáua & III-1997 & $23^{\circ} 38^{\prime} 18,9^{\prime \prime}$ & $46^{\circ} 37^{\prime} 31,6^{\prime \prime}$ \\
& $18-V I I I-1991$ & & \\
Hidrofitotério & $18-V I I-1991$ & $23^{\circ} 38^{\prime} 19,7^{\prime \prime}$ & $46^{\circ} 37^{\prime} 16,3^{\prime \prime}$ \\
& $7-X I-1996$ & & \\
\hline
\end{tabular}


de macrófitas aquáticas emergentes. No caso de substrato duro como rocha, por exemplo, a coleta foi feita raspando o substrato com canivete ou lâmina de barbear. Todo material foi coletado em duplicata. Uma parte do substrato amostrado foi fixada no próprio local de coleta e a outra no laboratório, após remoção do perifíton. As amostras foram fixadas e preservadas utilizando solução aquosa de formalina a 3-5\% (Bicudo \& Menezes 2006).

As amostras foram oxidadas e preparadas segundo método em Simonsen (1974) modificado por Moreira-Filho \& Valente-Moreira (1981), ou seja, efetuando a digestão com $\mathrm{K}_{2} \mathrm{MnO}_{4}$ e $\mathrm{HCl}$. O outro método utilizado seguiu os padrões da Comissão Europeia para Padronização (ECS, "European Comittee for Standartization" 2003) pelo qual $\mathrm{o}_{2} \mathrm{O}_{2}$ é previamente aquecido. Os dois métodos tiveram como finalidade remover o material orgânico para melhor analisar as valvas em lâminas permanentes. Naphrax $($ I.R. = 1,74), Hyrax (I.R. = 1,67) e Zyrax (I.R. = 1,7) foram os meios de inclusão empregados dependendo da disponibilidade momentânea.

Para exame das lâminas permanentes acima preparadas foram utilizados microscópio óptico binocular marca Zeiss modelo Axioskop 2 equipado com contraste de fase, câmara-clara e ocular micrometrada digital acoplados ao sistema óptico do Laboratório de Ecologia Aquática.

O estudo taxonômico foi baseado, sempre que possível, na análise de população, com ilustração dos táxons, tomada de medidas dos eixos apical e transapical e contagem do número de estrias, fíbulas, canais alares ou costelas valvares em intervalos de $10 \mu \mathrm{m}$. As medidas do comprimento total (eixo apical) e da largura máxima (eixo transapical) da valva foram tomadas diretamente usando ocular micrometrada digital acoplada ao sistema óptico do microscópio de captura de imagem.

A identificação dos respectivos materiais baseou-se em trabalhos clássicos e recentes dos tipos flora, monografia e revisão. Foram também utilizados alguns trabalhos menos abrangentes geograficamente e/ou referentes a uma ou outra espécie ou a grupos de espécies.

$\mathrm{O}$ enquadramento taxonômico baseou-se em Medlin \& Kaczmarska (2004) para as categorias supraordinais e Round et al. (1990) para as subordinais.

Informações dos principais locais de coleta encontram-se na tabela 1.

\section{Resultados e Discussão}

Os gêneros coletados no PEFI possuem o seguinte enquadramento taxonômico:
Divisão Bacillariophyta Haeckel 1878 (= Diatomea Dumortier 1821 in Adl et al. 2005)

Subdivisão Bacillariophytina Medlin \& Kaczmarska 2004

Classe Bacillariophyceae Haeckel 1878 emend. Medlin \& Kaczmarska 2004

Subclasse Bacillariophycideae D.G.Mann in Round et al. 1990

Ordem Surirellales D.G.Mann in Round et al. 1990

Família Surirellaceae Kützing 1844

Surirella Turpin 1828

Stenopterobia Brébisson ex van Heurck 1896

Chave para identificação dos gêneros inventariados:

1. Valva sempre isopolar, estreita, linear a linear-lanceolada ou sigmoide, área central claramente delimitada; ausência de saliências em forma de espinhos ou papilas na face valvar .......................................... Stenopterobia

1. Valva iso- ou heteropolares, de formas variadas; sistema de rafe elevado por quilha rasas ou profundas, claramente visíveis; presença de ondulações na área central, além de papilas ou espinhos Surirella

\section{Surirellaceae D.G. Mann (1990)}

A família Surirellaceae compreende os espécimes de vida solitária (Rabenhorst 1853) que possuem rafe marginal, a qual se comunica com o interior celular através de pórtulas sustentadas por fíbulas ou canais alares. Surirellaceae possuem o maior número de gêneros (sete) e cerca de 1.900 espécies, sendo a maior família entre as três que compõem a ordem (Ruck 2010). As espécies que a constituem são claramente definidas pela construção do canal de rafe elevado em quilhas (Round et al. 1990). Na grande maioria das espécies, o canal da rafe circunda toda a superfície valvar e, em algumas exceções, o mesmo é brevemente interrompido nos polos (Krammer 1988). A superfície valvar das espécies é geralmente plana, ondulada ou formada por costelas ou cumes e raramente atingem a região axial. As aréolas percorrem toda a face valvar e são geralmente interrompidas por nervuras ou outros elementos (Gasse 1986, Krammer 1988). Segundo Krammer (1988), a construção valvar das Surirellaceae possui alta resistência estática, entretanto, é susceptível a rápidas alterações de 
temperatura. Em termo de forma, as Surirellaceae são divididas por alguns autores (ex. Hustedt 1985) em duas subfamílias: Campylodiscoidae (inclui as formas arqueadas e em forma de sela constituídas por eixos apicais que se cruzam em ângulos retos) e Surireloideae (compreende as formas com eixos apicais que não se cruzam).

Stenopterobia L.A. Brébisson ex H. van Heurck

O gênero Stenopterobia é característico por reunir espécimes com valvas estreitas, alongadas, sigmoides ou retilíneas, lineares a linear-lanceoladas, de ápices arredondados, estreitos, sempre isopolares. A face valvar possui nervuras externas transapicais ou costas compostas por uma região mediana estreita ou uma ampla zona hialina (Krammer 1989, Siver \& Camfield 2007). As estrias são multisseriadas e constituídas por minúsculos poroides arredondados (Round et al. 1990). O sistema de rafe é elevado por quilhas e auxiliado por canais alares que alternam com as aberturas fenestrais (Krammer 1988). A presença de aréolas sem revestimento interno e terminações da rafe dilatadas em ambos os polos, são características importantes que diferenciam do gênero Surirella (Siver \& Camfield 2006, Ruck \& Kociolek 2004).

As espécies que constituem o gênero são geralmente planctônicas e presentes em corpos d'agua ácidos oligotróficos; mas, também podem ser bentônicas (Round et al. 1990, Lowe 2003). Atualmente são conhecidos ca. 55 táxons distribuídos mundialmente (Fourtanier \& Kociolek 2016). Recentemente, Cocquyt et al. (2014) contribuíram com a descrição de uma nova espécie bentônica encontrada em uma cachoeira em Zâmbia, na África. Para o Brasil, seis espécies e duas variedades são conhecidas (Eskinazi-Leça et al. 2016, Menezes et al. 2016).

Chave para as espécies inventariadas de Stenopterobia

1. Valva retilínea S. delicatissima

1. Valva sigmoide

2. Valva fortemente sigmoide

2. Valva levemente sigmoide

3. Ápices delicadamente arredondados

S. planctonica

3. Ápices largos e fortemente arredondados S. curvula

Stenopterobia curvula (W. Smith) K. Krammer, Bibliotheca Diatomologica 15: 108, pl. 58. 1987. Figuras 1-2
Valvas isopolares, simétricas, sigmoides, extremidades arredondadas, robustas, área axial hialina, estreita, canais alares delicados, costelas ausentes, fíbulas e estrias visíveis, paralelas, ausência de ornamentação na face valvar; 162,3-177,7 $\mu \mathrm{m}$ compr., 6-6,7 $\mu \mathrm{m}$ larg., Rc/1 24,1-28, 19-20 estrias em $10 \mu \mathrm{m}, 4-6$ fíbulas em $10 \mu \mathrm{m}$.

Hábitat: fitoplâncton.

Material examinado: BRASIL. São PAULO: São Paulo, Parque Estadual das Fontes do Ipiranga, Centro de Ciência e Tecnologia, lago, 15-I-1997, D.C. Bicudo \& L.L. Morandi (SP294907).

A população examinada mostrou eixos valvar e pervalvar semelhantes aos de Stenopterobia curvula (W. Smith) K. Krammer ilustrada em Kramer \& Lange-Bertalot (1988), embora pareçam visualmente diferentes. Os espécimes coletados no PEFI possuem valvas mais robustas e sigmoides. Outra diferença reside no número de estrias no intervalo de $10 \mu \mathrm{m}$, que é menor na população encontrada.

Para o Brasil, a espécie foi citada pela primeira vez para o Estado de São Paulo por Almeida \& Bicudo (2014) em um estudo sobre as diatomáceas planctônicas das represas de Pedro Beicht e Cachoeira da Graça, Sistema Alto Cotia, Município de Cotia. Os espécimes descritos para o PEFI concordam com os valores do comprimento e da largura fornecidos pelas autoras acima (compr. 158,0-202,1 $\mu \mathrm{m}$; larg. 6,6-7,5 $\mu \mathrm{m})$.

$\mathrm{Na}$ área de estudo, distribuiu-se em 3,5\% das amostras em condição oligotrófica.

Stenopterobia delicatissima (F. W. Lewis) L.A.Brébisson ex H. van Heurck, A treatise on the Diatomaceae. 374. 1896 E Surirella delicatissima F.W. Lewis, Proceedings of the Academy of Natural Sciences of Philadelphia 15: 343, pl. 1, fig. 4. 1864. Figuras 3-6

Valvas isopolares, simétricas, delgadas, lineares a linear-lanceoladas, extremidades arredondadas, acuminadas, podendo ser finas e longas nas frústulas maiores, área axial estreita, hialina, canais alares delicados, distintos, costelas e fíbulas ausentes, estrias paralelas, muitas vezes não visíveis ao microscópio de luz; 28-45,5 $\mu$ m compr., 4,2-5,4 $\mu \mathrm{m}$ larg., Rc/1 6-9,9, 6-10 canais alares em $10 \mu \mathrm{m}$.

Hábitat: fitoplâncton e perifíton.

Material examinado: BRASIL. São Paulo: São Paulo, Parque Estadual das Fontes do Ipiranga, 

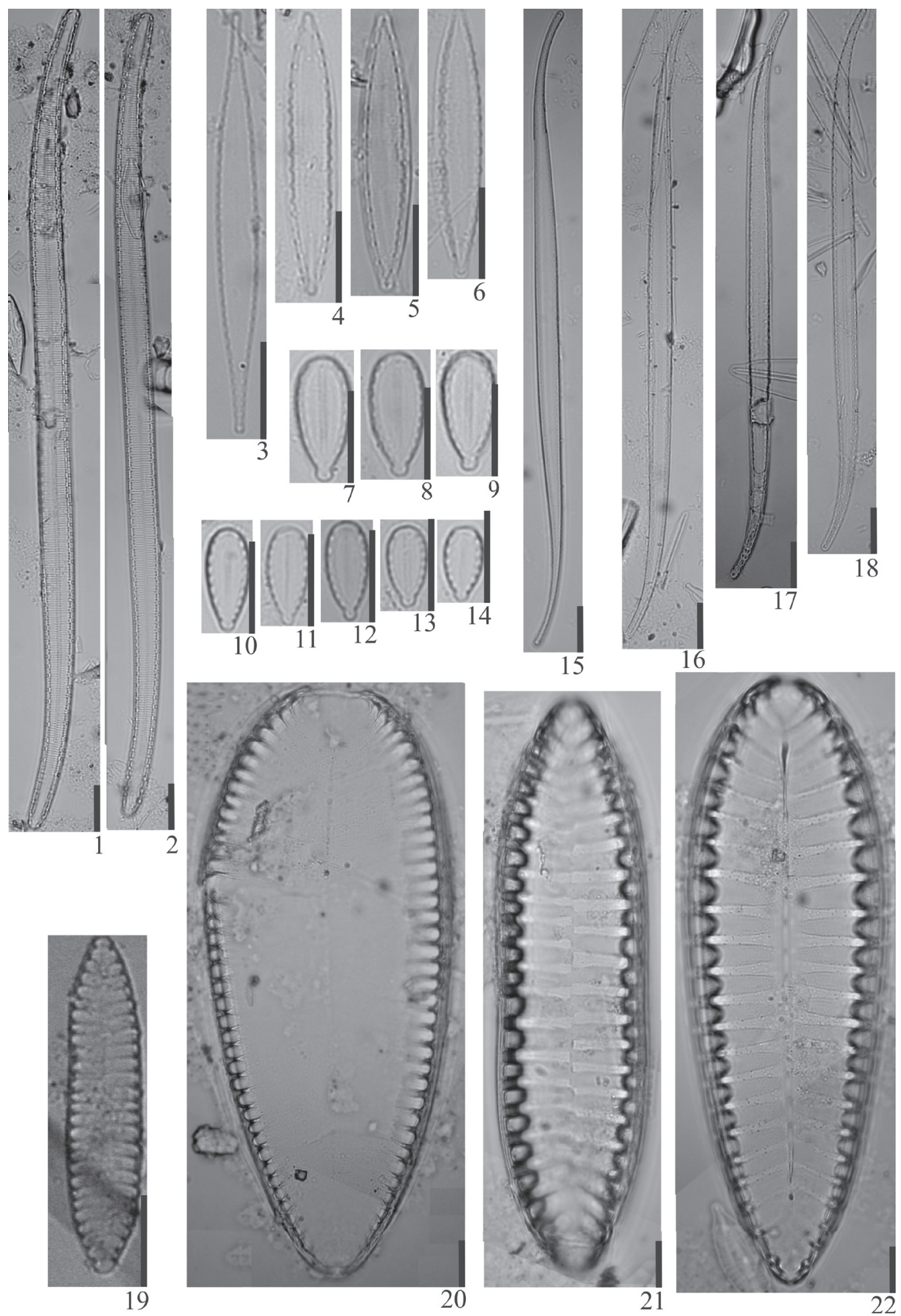

Figuras 1-22. Representantes de Surirellales. 1-2. Stenopterobia curvula (W.Smith) K. Kramer. 3-6. Stenopterobia delicatissima (F.W. Lewis) L.A. Brébisson ex H. van Heurck. 7-14. Surirella stalagma M.H. Hohn \& J. Hellerman. 15. Stenopterobia pelagica F. Hustedt. 16-18. Stenopterobia planctonica D. Meltzeltin \& H. Lange-Bertalot. 19. Surirella angusta F.T. Kützing. 20. Surirella guatimalensis C.G. Ehrenberg. 21. Surirella robusta C.G. Ehrenberg. 22. Surirella splendida (C.G. Ehrenberg) F.T. Kützing. Barra de escala = $10 \mu \mathrm{m}$.

Figures 1-22. Surirellales representatives. 1-2. Stenopterobia curvula (W.Smith) K. Kramer. 3-6. Stenopterobia delicatissima (F.W. Lewis) L.A. Brébisson ex H. van Heurck. 7-14. Surirella stalagma M.H. Hohn \& J. Hellerman. 15. Stenopterobia pelagica F.Hustedt. 16-18. Stenopterobia planctonica D.Meltzeltin \& H. Lange-Bertalot. 19. Surirella angusta F.T. Kützing. 20. Surirella guatimalensis C.G. Ehrenberg. 21. Surirella robusta C.G. Ehrenberg. 22. Surirella splendida (C.G. Ehrenberg) F.T. Kützing. Scale bar $=10 \mu \mathrm{m}$. 
Jardim Botânico de São Paulo, córrego Pirarungáua, 18-VIII-1991, D.C. Bicudo, T.A.V. Ludwig \& D.M. Figueiredo (SP255749); hidrofitotério, 7-VI-2011, P.D.A. Silva, G.C. Marquadt, S.W. Ribeiro \& B. Pelegrini (SP427342); Centro de Ciência e Tecnologia, lago, 15-I-1997, D.C. Bicudo \& L.L. Morandi (SP294907).

Os espécimes ora examinados concordaram com o lectótipo designado em Siver \& Camfield (2007) no que se refere aos valores do eixo valvar $(34-68 \mu \mathrm{m})$, embora alguns dos atuais espécimes possuam medidas do eixo pervalvar maiores do que as do material tipo da espécie $(3,5-5 \mu \mathrm{m})$.

As menores valvas dos exemplares do PEFI lembram as de $S$. pseudodelicatissima A. Siver \& P.B. Hamilton (2005) graças ao formato valvar simétrico, elíptico-lanceolado e aos ápices acuminados e arredondados, no entanto, diferem nos valores do comprimento e da largura que em $S$. delicatissima (F.W. Lewis) L.A. Brébisson ex H. van Heurck são maiores quando comparados com os de $S$. pseudodelicatissima (compr. 10-16 $\mu \mathrm{m}$, larg. 3,2-4 $\mu \mathrm{m}$ ). Outra diferença a ser salientada reside na área central de $S$. pseudodelicatissima que é proporcionalmente maior e possui estrias relativamente curtas.

A espécie foi ilustrada e descrita por Fürstenberger \& Valente-Moreira (2000) para a região Sul do Brasil. O valor de comprimento $(55,3 \mu \mathrm{m})$ anotado pelos referidos autores é maior do que os valores encontrados na população presentemente estudada. Em contrapartida, o valor correspondente à largura é menor $(3,5 \mu \mathrm{m})$ do que os valores encontrados neste estudo. Para a região Norte, a espécie foi ilustrada por Aprile \& Meira (2007). Oliveira et al. (2012) ilustraram e descreveram a espécie para a região Centro-Oeste do país. Os últimos autores mediram exemplares cujo comprimento e largura foram maiores (compr. 22-96 $\mu \mathrm{m}$, larg. 4-11 $\mu \mathrm{m}$ ) do que os atualmente referidos para a população do PEFI. Para São Paulo, a espécie foi ilustrada e descrita por Almeida \& Bicudo (2014). Apesar da semelhança desse material com o atualmente estudado, os espécimes identificados pelas autoras acima possuem medidas valvares maiores (compr. 62-71 $\mu \mathrm{m}$ e larg. 6,7-7,2 $\mu \mathrm{m}$ ).

$\mathrm{Na}$ área de estudo, a espécie ocorreu em 10,7\% das amostras de ambientes com condições oligotrófica e mesotrófica.

Stenopterobia pelagica F. Hustedt, Internationale RevuederGesamten HydrobiologieundHydrographie 42: 143, fig. 358. 1942.

Figura 15
Valvas isopolares, simétricas, sigmoides, extremidades arredondadas, estreitas, fletidas em sentidos opostos, área axial hialina, estreita, canais alares delicados, costelas e fíbulas ausentes, estrias inconspícuas, ornamentação na face valvar não visível ao microscópio de luz; 118,3-133 $\mu \mathrm{m}$ compr., 4,7-5,8 $\mu \mathrm{m}$ larg., Rc/1 22,8-28,4, 5-7 canais alares em $10 \mu \mathrm{m}$.

Hábitat: epilíton e perifíton.

Material examinado: BRASIL. São Paulo: São Paulo, Parque Estadual das Fontes do Ipiranga, Jardim Botânico, Lago das Ninfeias, 18-VII-1991, D.C. Bicudo, T.A.V. Ludwig \& D.M. Figueiredo (SP255743); 7-XI-1996, D.C. Bicudo \& L.L. Morandi (SP294899); hidrofitotério, 18-VII-1991, D.C. Bicudo, T.A.V. Ludwig \& D.M. Figueiredo (SP255745b); 7-XI-1996, D.C. Bicudo \& L.L. Morandi (SP294903); Lago do Monjolo, III-1997, D.C. Bicudo \& L.L. Morandi (SP294909); material sobre musgos e tronco de árvore, 7-VI-2011, P.D.A. Silva, G.C. Marquadt, S.W. Ribeiro \& B. Pelegrini (SP427344, SP427346).

Os exemplares ora identificados são semelhantes aos do lectótipo de $S$. pelagica F. Hustedt ilustrados em Simonsen (1987), por conta das valvas sigmoides de ápices arredondados. Stenopterobia pelagica difere de Stenopterobia planctonica D. Metzeltin \& H. LangeBertalot (1998) pelo comprimento do eixo valvar, que é maior em $S$. pelagica (S. pelagica possui comprimento $>100 \mu \mathrm{m}$ e $S$. planctonica $\leq 100 \mu \mathrm{m}$ ) e pelas medidas do eixo pervalvar menores em $S$. planctonica $(3,5-4$ $\mu \mathrm{m})$. Acrescente-se o número de canais alares, que $S$. pelagica possui 6-9 em $10 \mu \mathrm{m}$ e $S$. planctonica 5-7 em $10 \mu \mathrm{m}$. Ambas as espécies são morfologicamente diferentes desde que $S$. pelagica possui valvas relativamente mais sigmoides e extremidades mais arredondadas do que em S. planctonica. Outra diferença está nos ápices valvares, que em $S$. planctonica são mais estreitos e levemente arredondados e em $S$. pelagica são nitidamente arredondados.

Para o Brasil, a espécie foi ilustrada e descrita para a região Centro-Oeste por Oliveira et al. (2012). Os valores do comprimento e da largura valvares mencionados pelos referidos autores assemelham-se aos valores encontrados no Estado de São Paulo (compr. 98-140 $\mu \mathrm{m}$ e larg. 5-6 $\mu \mathrm{m}$ ).

A espécie ocorreu em 25\% das amostras estudadas em locais de condição mesotrófica.

Stenopterobia planctonica D.Metzeltin \& H.LangeBertalot, Iconografia Diatomologica 5: 672, pl. 219, fig. 3. 1998.

Figuras 16-18 
Valvas isopolares, simétricas, isobilaterais, lineares a linear-lanceoladas, sigmoides, extremidades arredondadas, área axial hialina, estreita, canais alares delicados, costelas e fíbulas ausentes, estrias quando visíveis finas, paralelas, presentes em toda superfície valvar; 93,6-124,3 $\mu \mathrm{m}$ compr., 4,1-4,9 $\mu \mathrm{m}$ larg., Rc/1 22-26,6, ca. 6 canais alares em $10 \mu \mathrm{m}, 22-25$ estrias em $10 \mu \mathrm{m}$.

Hábitat: perifíton.

Material examinado: BRASIL. São PAUlo: São Paulo, Parque Estadual das Fontes do Ipiranga, Jardim Botânico, Lago do Monjolo, III-1997, D.C. Bicudo \& L.L. Morandi (SP294909).

Segundo Metzeltin \& Lange-Bertalot (1998), $S$. planctonica D.Metzeltin \& H.Lange-Bertalot possui medidas do eixo valvar inferiores a $100 \mu \mathrm{m}$, eixo pervalvar 3,5-4 $\mu \mathrm{m}$ e número de estrias variável entre 25 e 29 . A população coletada no PEFI possui características morfológicas semelhantes às descritas e ilustradas por Metzeltin \& Lange-Bertalot (1998). É semelhante também no que refere o número de estrias em $10 \mu \mathrm{m}$ (23-29 estrias), porém, os valores dos eixos valvar $(93,6-124,3 \mu \mathrm{m})$ e pervalvar $(4,1-4,9 \mu \mathrm{m})$ são maiores do que os do tipo nomenclatural em Metzeltin \& Lange-Bertalot (1998).

Stenopterobia planctonica difere de Stenopterobia pelagica $\mathrm{F}$. Hustedt no comprimento do eixo valvar $(<100 \mu \mathrm{m})$, na largura do eixo pervalvar da ordem de 6-7 $\mu \mathrm{m}$ e no número de estrias entre 34 e 36 em $10 \mu \mathrm{m}$.

Embora os espécimes coletados no PEFI possuam medidas que melhor se enquadram no espectro de variação de $S$. pelagica, ambas são morfologicamente diferentes, principalmente no formato sigmoide e na terminação valvar mais acentuada em S. pelagica.

Para o Brasil, a espécie foi descrita e ilustrada para região Sul em Santos et al. (2011). As populações encontradas no Estado do Paraná apresentaram valores de comprimento $(87,2-164,8 \mu \mathrm{m})$ maiores do que os exemplares descritos para o Estado de São Paulo.

A espécie ocorreu em 3,5\% das amostras estudadas em condição mesotrófica.

\section{Surirella P.J.F. Turpin}

O gênero Surirella é constituído por indivíduos de hábito solitário (Brun 1880), com frústulas iso- ou heteropolares em forma de cunha e que possuem um ou dois plastídios marginais altamente lobados, que podem ser observados mesmo quando a matéria orgânica não é removida. Podem também ser encontrados espécimes cujas valvas são torcidas sobre o eixo apical (Krammer \& Lange-Bertalot 1988, Lowe 2003). O gênero possui grande variabilidade de formas, que vão do linear ao elíptico e ao obovado e também podem, algumas vezes, ser panduriformes. Contudo, são sempre altamente silicificadas. Cada valva possui duas rafes localizadas nas margens elevadas por quilhas rasas ou profundas (Round et al. 1990). Difere do gênero Stenopterobia pela face valvar constituída de ornamentação e pelas estrias compostas por pequenos poroides, os quais são, em geral, interrompidos pelo esterno (Round et al. 1990).

$\mathrm{O}$ gênero é dominantemente encontrado na água doce, porém, existem algumas espécies marinhas (Round et al. 1990). São comuns no bentos, especialmente em hábitats epipélicos, mas também podem ocupar o plâncton (Torgan \& Weber 2008), epilíton e o epifíton (Spaulding \& Edlun 2010, Lowe 2003).

Mundialmente, são conhecidas por volta de 505 espécies de Surirella (Karthick et al. 2012, Cvetkoska et al. 2014, Cocquyt \& Taylor 2015, Fourtanier \& Kociolek 2016). Para o Brasil, foram registradas 41 espécies e 13 variedades segundo Eskinazi-Leça et al. (2016) e Menezes et al. (2016).

Chave para as espécies inventariadas de Surirella

1. Valva isopolar

2. Canais alares bem marcados

S. robusta

2. Canais alares pouco marcados

3. Canais alares que não estendem até à área axial Surirella sp. 4

3. Canais alares delicados que estendem até à área axial

4. Extremidade valvar arredondada Surirella sp. 2

4. Extremidade valvar cuneada, rostrada a subcapitada S. angusta

1. Valva heteropolar

5. Valva fortemente heteropolar, presença de área hialina na extremidade apical S. guatimalensis

5. Valva não fortemente heteropolar, área hialina ausente na extremidade apical 
6. Comprimento do eixo apical valvar $<25 \mu \mathrm{m}$

7. Valva espatulada

S. stalagma

7. Valva de outras formas

8. Valva mais longa que larga Surirella sp. 1

8. Valva mais larga que longa Surirella sp. 3

6. Comprimento do eixo apical valvar $>25 \mu \mathrm{m}$

9. Valvas destituídas de espinhos Surirella sp. 5

9. Valvas com espinhos em 1 ou 2 extremidades

10. Ápice posterior cuneiforme

S. tenera

10. Ápice posterior cuneiforme-arredondado

S. splendida

Surirella angusta F.T. Kützing, Die Kieseslchaligen Bacillarien oder Diatomeen. 61, pl. 30, fig. 52.1844 三 Surirella ovalis L.A. Brébisson var. angusta (F.T. Kützing)H. van Heurck (1885); Surirella ovalis L.A. Brébisson var. angusta (F.T. Kützing) R. Gutwinski (1899); Surirella ovalis L.A. Brébisson var. angusta (F.T. Kützing) A. Cleve (1952).

Figura 19

Valvas isopolares, simétricas, isobilaterais, lineares a linear-lanceoladas, margens paralelas, extremidades cuneadas, rostradas a subcapitadas, área axial linear, hialina, estreita, canal alar e costelas ausentes, fíbulas paralelas na região mediana, radiadas nas extremidades, quilha baixa, estrias paralelas, visíveis ao microscópio óptico; ca. $36,3 \mu \mathrm{m}$ compr., ca. $8,1 \mu \mathrm{m}$ larg., Rc/1 4,5, ca. 7 canais alares em $10 \mu \mathrm{m}$.

Hábitat: epilíton.

Material examinado: BRASIL. São PAULO: São Paulo, Parque Estadual das Fontes do Ipiranga, Jardim Botânico, material sobre musgos e tronco de árvore, 7-VI-2011, P.D.A. Silva, G.C. Marquadt, S.W. Ribeiro \& B. Pelegrini (SP427346b).

A espécie é típica por possuir valvas isopolares segundo o eixo apical e forma linear, com margens paralelas e ápices cuneados (Lange-Bertalot 2005). Surirella angusta apresenta pequenas ondulações na face valvar, que podem ser visíveis ao microscópio óptico (Lange-Bertalot 2005, Vyvermann 1991).

Surirella angusta é comparável a Surirella antioquiensis S.E. Sala, J.J. Ramírez, Plata-Díaz \& Vouilloud (2013) por conta do formato linear e isopolar das valvas, no entanto, difere nos valores do comprimento e da largura valvares que são menores em $S$. antioquiensis (eixo valvar 14-32 $\mu$ m, eixo pervalvar 6,4-7,6 $\mu \mathrm{m}$ ). Segundo Sala et al. (2013), as maiores diferenças entre as duas espécies são observadas ao microscópio eletrônico de varredura e são: (1) organização unisseriada das estrias em S. antioquiensis; (2) formato delicado e pouco perceptível das costas em $S$. antioquiensis e costas numerosas e bem evidentes em $S$. angusta; (3) área axial ampla em $S$. antioquiensis; e (4) densidade de fíbulas e aréolas em intervalo de $10 \mu \mathrm{m}$.

Surirella amphioxys W. Smith pode ser comparada com S. angusta devido ao formato isopolar das valvas e às fíbulas marcadas, que se estendem até à região mediana das valvas; no entanto, S. amphioxys possui dimensões menores do eixo valvar (ca. $30,5 \mu \mathrm{m}$ ) e maiores do eixo pervalvar (ca. 12,7 $\mu \mathrm{m}$ ), além do que nos espécimes menores de $S$. amphioxys a área central adquire forma acentuadamente lanceolada (English 2016).

Surirella minuta L.A.Brébisson ex F.T.Kützing (1849) também é comparável a $S$. angusta devido às fíbulas bem visíveis, que se estendem até à área central, porém, difere pelas valvas heteropolares e pelos ápices amplamente arredondados, diferente de $S$. angusta que os possui cuneados, rostrados a subcapitados (English 2016).

No Brasil, a espécie foi ilustrada para a região Sul do país no trabalho de Silva et al. (2010) para o Reservatório do Iraí, Estado do Paraná. No entanto, os autores não forneceram valores métricos e merísticos. Ainda para o Estado do Paraná, Santos et al. (2011) forneceram medidas do comprimento $(32,4-39,5 \mu \mathrm{m})$ e da largura $(7,1-7,9 \mu \mathrm{m})$ de espécimes da população coletada em macrófitas aquáticas. Bartozek et al. (2013) ilustraram e descreveram a espécie para o Parque Nacional do Iguaçu. O trabalho forneceu medidas do comprimento $(28-39 \mu \mathrm{m})$ e da largura $(6,4-8 \mu \mathrm{m})$ correspondentes aos valores dos espécimes do Estado de São Paulo. Para o Estado de Santa Catarina, Burliga et al. (2005) registraram Surirella angusta em amostras epilíticas do rio Itajaí-Mirim. As medidas fornecidas (compr. 28-42,4 $\mu \mathrm{m}$; larg. 8-8,4 $\mu \mathrm{m}$ ) são correspondentes ao valor encontrado no presente estudo. Para o Estado do Rio Grande do Sul, Flôres et al. (1999) e Laux \& Torgan (2011) registraram, respectivamente, espécimes de Surirella 
angusta para o Banhado do Taim e para a foz dos rios do Delta do Jacuí. Ambos os trabalhos forneceram ilustrações e medidas. No Estado de São Paulo, Moutinho et al. (2007) registraram a presença de um exemplar semelhante a Surirella angusta e juntaram a medida do comprimento $(41 \mu \mathrm{m})$ desse exemplar do reservatório de Cabuçu, Município de Guarulhos. No entanto, as ilustrações fornecidas pelos referidos autores não correspondem às características de Surirella angusta.

No presente estudo, a espécie ocorreu em 3,5\% das amostras analisadas.

Surirella guatimalensis C.G. Ehrenberg, Mikrogeologie: das erden und felsen schaffende Wirken des unsichtbar kleinen selbstständigen Lebens auf der Erde. 19, pl. 33, fig. 7. 1854.

Figura 20

Valvas heteropolares, assimétricas, extremidade apical amplamente arredondada, porção hialina no centro, extremidade basal cuneada a arredondada, área axial larga, canais alares visíveis, curtos, não alcançando a área central, costelas ausentes, fíbulas ausentes, quilha alta, estrias não visíveis; ca. 197,5 $\mu \mathrm{m}$ compr., ca. 83,9 $\mu \mathrm{m}$ larg., Rc/1 2,35, ca. 2 canais alares em $10 \mu \mathrm{m}$.

Hábitat: perifíton/metafíton.

Material examinado: BRASIL. São PAUlo: São Paulo, Parque Estadual das Fontes do Ipiranga Centro de Ciência e Tecnologia, brejo do lago, 15-I-1997, D.C. Bicudo \& L.L. Morandi (SP294908).

A presente espécie lembra, quanto à morfologia, Surirella davidsonii A.Schmidt (1875) descrita e ilustrada em Oliveira et al. (2012) devido à heteropolaridade valvar, à área axial larga e aos canais alares curtos que não alcançam o centro da valva; no entanto, S. davidsonii possui valores do comprimento (90-138 $\mu \mathrm{m})$ e da largura $(33-60 \mu \mathrm{m})$ valvares menores do que os de Surirella guatimalensis. Outra diferença está na ausência de uma porção hialina localizada na extremidade apical das valvas de $S$. guatimalensis, que não foi observada em $S$. davidsonii.

No Brasil, Surirella guatimalensis foi registrada nos trabalhos para a região Sul por Teixeira \& Kutner (1960), Flôres et al. (1999), Souza-Mosimann et al. (2010) e Salomoni \& Torgan (2010). Para Santa Catarina, Souza-Mosimann et al. (2010) apenas ilustraram a espécie, não fornecendo dados métricos nem merísticos. Para o Rio Grande do Sul, Teixeira \& Kutner (1960) ilustraram e descreveram uma população com valores de comprimento (116-208 $\mu \mathrm{m})$ e largura (56-94 $\mu \mathrm{m})$ semelhantes aos do exemplar em estudo. Flôres et al. (1999) registrou valores correspondentes a largura $(51,0-82.0 \mu \mathrm{m})$ e maiores valores para o comprimento $(109-153,8 \mu \mathrm{m})$. Por fim, Salomoni \& Torgan (2010) apresentaram valores menores do comprimento $(130 \mu \mathrm{m})$ e da largura $(55 \mu \mathrm{m})$.

Ocorreu em 3,5\% das amostras analisadas de ambientes oligotróficos.

Surirella robusta C.G. Ehrenberg var. robusta Verhandlugen der Königlich-PreussischenAkademie der Wissenschaften zu Berlin. 215. 1840.

\section{Figura 21}

Valvas isopolares, simétricas, isobilaterais, lineares a linear-lanceoladas, levemente constritas na parte média, extremidades cuneadas, área axial estreita, hialina, não estendendo até os ápices, canais alares paralelos, costelas paralelas entre si, fíbulas ausentes, quilha elevada, estrias não visíveis; 121,5-172,5 $\mu \mathrm{m}$ compr., 32,8-37 $\mu \mathrm{m}$ larg., Rc/1 $3,5-4,7,1-2$ canais alares em $10 \mu \mathrm{m}, 1-2$ costelas em $10 \mu \mathrm{m}$.

Hábitat: fitoplâncton e perifíton.

Material examinado: BRASIL. SÃo PAULO: São Paulo, Parque Estadual das Fontes do Ipiranga, Centro de Ciência e Tecnologia, lago, 15-I-1997, D.C. Bicudo \& L.L. Morandi (SP294906, SP294907).

Surirella robusta possui, frequentemente, valvas obovadas, de ápices estreitos, apiculados a arredondados. Heteropolar na grande maioria de seus representantes (River 1974, Germain 1981), a espécie é característica por possuir quilhas situadas em canais alares bem desenvolvidos, projetados acima da face valvar (Lange-Bertalot 2005). A valva possui área central lanceolada a linear-lanceolada, com costelas robustas (River 1974, van Heurck 1885) e estrias delicadas não visíveis ao microscópio óptico.

Surirella robusta var. robusta difere de $S$. robusta var. armata F. Hustedt (1937) pela isopolaridade valvar, além das costelas bem marcadas que não são observadas na variedade-tipo da espécie. Outra diferença está na área central de $S$. robusta var. armata que, nesta última, possui pequenas pontuações que se estendem até às extremidades das valvas.

Surirella biseriata L.A. Brébisson var. constricta A. Grunow também pode ser comparada com S. robusta devido à isopolaridade das valvas, às extremidades cuneadas, às costelas paralelas entre 
si e aos canais alares bem marcados. Contudo, esses dois materiais diferem pelo fato da constrição mediana em S. biseriata var. constricta não estar situada ao longo do eixo longitudinal mediano da valva, além dos valores do comprimento e da largura valvares serem menores em $S$. biseriata var. constricta (compr. 80-350 $\mu \mathrm{m}$, larg. 30-80 $\mu \mathrm{m}$ ).

Para o Brasil, a espécie foi reportada para a região Sudeste por Graça et al. (2007) para o Estado de São Paulo, Município de Guarulhos. O exemplar ilustrado possui comprimento $(172,5 \mu \mathrm{m})$ semelhante àqueles do material do PEFI. No entanto, o valor de largura $(45 \mu \mathrm{m})$ é menor.

Surirella robusta var. robusta ocorreu em 7,1\% das amostras analisadas de ambientes oligotróficos.

Surirella splendida (C.G. Ehrenberg) F.T. Kützing, Die Kieselschaligen Bacillarien oder Diatomeen. 62, pl. 7, fig. 9. 1844 三 Navicula splendida C.G. Ehrenberg, Abhandlungen der Königlichen AkademieWissenschaften zu Berlin: Physikalische Klasse, 81. 1831

Figura 22

Valvas heteropolares, assimétricas, extremidade apical arredondada, extremidade basal cuneada, área axial hialina, lanceolada, 1 espinho pequeno na extremidade, canais alares vistosos, paralelos, costelas paralelas, fíbulas ausentes, quilha elevada, estrias não visíveis; 105,5-181,3 $\mu \mathrm{m}$ compr., 38,8-53,5 $\mu \mathrm{m}$ larg., $\mathrm{Rc} / 1$ 2,7-3,6, ca. 1 canal alar em $10 \mu \mathrm{m}, 1-3$ costelas em $10 \mu \mathrm{m}$.

Habitat: perifíton.

Material examinado: BRASIL. São Paulo: São Paulo, Parque Estadual das Fontes do Ipiranga, Jardim Botânico, Lago das Ninfeias, 7-XI-1996, D.C. Bicudo \& L.L. Morandi (SP294899); hidrofitotério, 7-VI-2011, P.D.A. Silva, G.C. Marquadt, S.W. Ribeiro \& B. Pelegrini (SP427342).

O presente material proveniente do PEFI difere de Surirella tenera W. Gregory (1856) pelos maiores valores do comprimento e da largura das valvas, assim como pelo formato valvar que em $S$. tenera é ligeiramente cuneado na extremidade basal, característica esta não observada em $S$. splendida (C.G.Ehrenberg) F.T. Kützing.

Surirella pinnigera A.J. Bramburguer \& P.B. Hamilton (2006) e Surirella splendidoides F. Hustedt (1965) lembram a espécie em pauta pela presença de um espinho em cada extremidade. Contudo, $S$. pinnigera possui a área axial relativamente menos expandida e que não alcança os ápices das valvas; e Surirella splendidoides possui valores menores do comprimento e da largura valvares, além de possuir estrias visíveis, características estas não observáveis em S. splendida.

Para o Brasil, a espécie foi descrita e ilustrada por Oliveira et al. (2012) para a região Centro-Oeste. Os espécimes coletados no Estado Goiás possuem características semelhantes às das populações do Estado de São Paulo (presença de papilas ao longo da face valvar e de um espinho próximo ao ápice). Contudo, o segundo espinho localizado na extremidade valvar não foi observado nos exemplares do PEFI. Outra diferença a ser mencionada está nos menores valores do comprimento e da largura das valvas fornecidos pelos autores antes referidos (compr. 77-100 $\mu \mathrm{m}$, larg. 30-35 $\mu \mathrm{m}$ ). Surirella splendida também foi identificada para a região Sul (Estado do Paraná) no estudo de Silva et al. (2010) sobre as diatomáceas perifíticas do reservatório do Iraí (sistema eutrófico). Os valores do comprimento e da largura valvares concordam com os obtidos no presente estudo (compr. 113,8 $\mu \mathrm{m}$, larg. 39,2 $\mu \mathrm{m}$ ). Ainda para o Estado do Paraná, Santos et al. (2011) registraram a presença da espécie ao estudar as diatomáceas perifíticas presentes em macrófitas aquáticas. Os autores forneceram medidas, mas não ilustrações (compr. 94,4-96,3 $\mu \mathrm{m}$, larg. 30,1-32,8 $\mu \mathrm{m}$ ) do material que identificaram. Por fim, Bartozek et al. (2013) ilustraram um espécime encontrado no Parque Nacional do Iguaçu. Medidas do comprimento e da largura das valvas também são fornecidas nesse trabalho (compr. 113.2-141 $\mu \mathrm{m}$, larg. 45.3-53.9 $\mu \mathrm{m}$ ).

Surirella splendida ocorreu em 7,1\% das amostras analisadas, coletadas de ambiente mesotrófico.

Surirella stalagma M.H. Hohn \& J. Hellerman, Transactions of the American Microscopical Society 82: 327, pl. 4, fig. 6. 1963.

Figuras 7-14

Valvas heteropolares, espatuladas, extremidade apical arredondada, extremidade basal capitada, área axial hialina, linha apical visível em alguns espécimes, canais alares e costelas ausentes, fíbulas curtas, largas, quilha baixa, estrias não visíveis ao microscópio óptico; 9,5-13,5 $\mu \mathrm{m}$ compr., 4,1-6,4 $\mu \mathrm{m}$ larg., Rc/1 1,9-2,5, ca. 7-10 fíbulas em $10 \mu \mathrm{m}$.

Hábitat: perifíton. 
Material examinado: BRASIL. São Paulo: São Paulo, Parque Estadual das Fontes do Ipiranga, Jardim Botânico, Lago das Ninfeias, 7-XI-1996, D.C. Bicudo \& L.L. Morandi (SP294899); hidrofitotério, 7-VI-2011, P.D.A. Silva, G.C. Marquadt, S.W. Ribeiro \& B. Pelegrini (SP427341, SP427342).

Esta espécie difere de Surirella atomus F. Hustedt (1995) pela extremidade basal capitada e a presença de fíbulas curtas. Outra espécie morfologicamente semelhante a $S$. stalagma é Surirella suecica A. Grunow (1881), desde que ambas possuem valvas heteropolares, eixo apical arredondado e eixo basal capitado. Contudo, S. suecica possui valvas clavadas (alguns exemplares), maiores tanto no comprimento quanto na largura (eixo valvar 14-34 $\mu \mathrm{m}$, eixo pervalvar 7-9,5 $\mu \mathrm{m}$ ) e fíbulas bem marcadas e visíveis.

No Brasil a espécie foi registrada para a região Sul nos trabalhos de Shirata \& Moreira (1987) realizados com material coletado no Parque São Lourenço em Curitiba. Os valores fornecidos pelos últimos autores são maiores em comprimento $(11,1-21,8 \mu \mathrm{m})$ e menores em largura $(4,8-5,3 \mu \mathrm{m})$ do que os encontrados no PEFI. Ainda para o Estado do Paraná, Santos et al. (2011) forneceram apenas as medidas das valvas (compr. 14,7 $\mu \mathrm{m}$, larg. 6,7 $\mu \mathrm{m}$ ) sem ilustrar o material que identificaram.

A presente espécie é citada pela primeira vez para o Estado de São Paulo. Ocorreu em 10,7\% das amostras analisadas de ambientes com condição mesotrófica.

Surirella tenera W. Gregory, Quarterly Journal of Microscopical Science: nova série, 4: 11, pl. 1, fig. 38. $1856 \equiv$ Surirella robusta C.G. Ehrenberg var. tenera (W. Gregory) H. van Heurck (1885), Bericht über die zur Bekanntmachung geeigneten Verhandlungen der Königlich-PreussischenAkademiederWissenschaften zu Berlin. 187. 1840.

Figuras 23-24

Valvas heteropolares, assimétricas, extremidade apical amplamente arredondada, extremidade basal ligeiramente cuneada a arredondada, área axial hialina, estreita, geralmente 1-2 espinhos em cada extremidade, canais alares vistosos, paralelos, costelas paralelas entre si, fíbulas ausentes, quilha elevada, estrias não visíveis ao microscópio óptico; 107,4-136,8 $\mu \mathrm{m}$ compr., 32,7-35,7 $\mu \mathrm{m}$ larg., Rc/1 3,2-3,8, 1-2 canais alares em $10 \mu \mathrm{m}, 2-3$ costelas em $10 \mu \mathrm{m}$.

Hábitat: perifíton.
Material examinado: BRASIL. São PAUlo: São Paulo, Parque Estadual das Fontes do Ipiranga, Jardim Botânico, Lago das Ninfeias, 7-XI-1996, D.C. Bicudo \& L.L. Morandi (SP294899); hidrofitotério, 7-VI-2011, P.D.A. Silva, G.C. Marquadt, S.W. Ribeiro \& B. Pelegrini (SP427341).

Surirella tenera W. Gregory é típica por possuir valvas heteropolares, com a extremidade apical fortemente arredondada e a basal cuneiformearredondada. Difere das demais espécies do gênero, principalmente, pela estrutura valvar mais delicada (geralmente mais de 25 canais alares em $100 \mu \mathrm{m}$ ), pelo tamanho relativamente menor de suas valvas, por possuir, em alguns casos, uma nervura mediana e espinhos salientes nas extremidades (Krammer \& Lange-Bertalot 1988).

A espécie pode ser comparada com Surirella splendida (C.G. Ehrenberg) F.T. Kützing (1844), no entanto, as dimensões do comprimento e da largura valvares permitem diferir uma espécie da outra. Assim, $S$. splendida possui eixo valvar que varia entre 70-250 $\mu \mathrm{m}$ e eixo pervalvar entre 40-70 $\mu \mathrm{m}$, sendo, portanto, maiores do que em $S$. tenera.

Pela presença de espinhos na extremidade apical e da semelhança das medidas do comprimento e da largura valvares, $S$. tenera também lembra Surirella pinnigera A.J. Bramburger \& P.B. Hamilton (2006), mas a última é distinta pela forma clavada de suas valvas (Bramburguer et al. 2006).

No Brasil, a espécie foi ilustrada e descrita para a região Centro-Oeste em Oliveira et al. (2012) para o Sistema Lago dos Tigres. Os valores métricos (compr. 85-150 $\mu \mathrm{m}$, larg. 26-37 $\mu \mathrm{m}$ ) encontram-se de acordo com aqueles obtidos no presente estudo. Para a região Sul, Flôres et al. (1999) registraram menores valores para $S$. tenera (compr. 63-83 $\mu \mathrm{m}$, larg. 19,1-28,9 $\mu \mathrm{m}$ ) durante o levantamento florístico efetuado para o Banhado do Taim, Estado do Rio Grande do Sul. Hermany et al. (2006) apenas ilustraram a espécie em trabalho sobre as diatomáceas epilíticas da Região Hidrográfica de Guaíba. Ainda para o Estado do Rio Grande do Sul, Salomoni \& Torgan (2010) reportaram S. tenera var. subconstricta para o Parque Estadual Delta do Jacuí. O trabalho forneceu medidas e ilustração.

A espécie ocorreu em $7,1 \%$ das amostras analisadas de ambientes com condição mesotrófica.

Surirella sp. 1

Figuras 25-27 

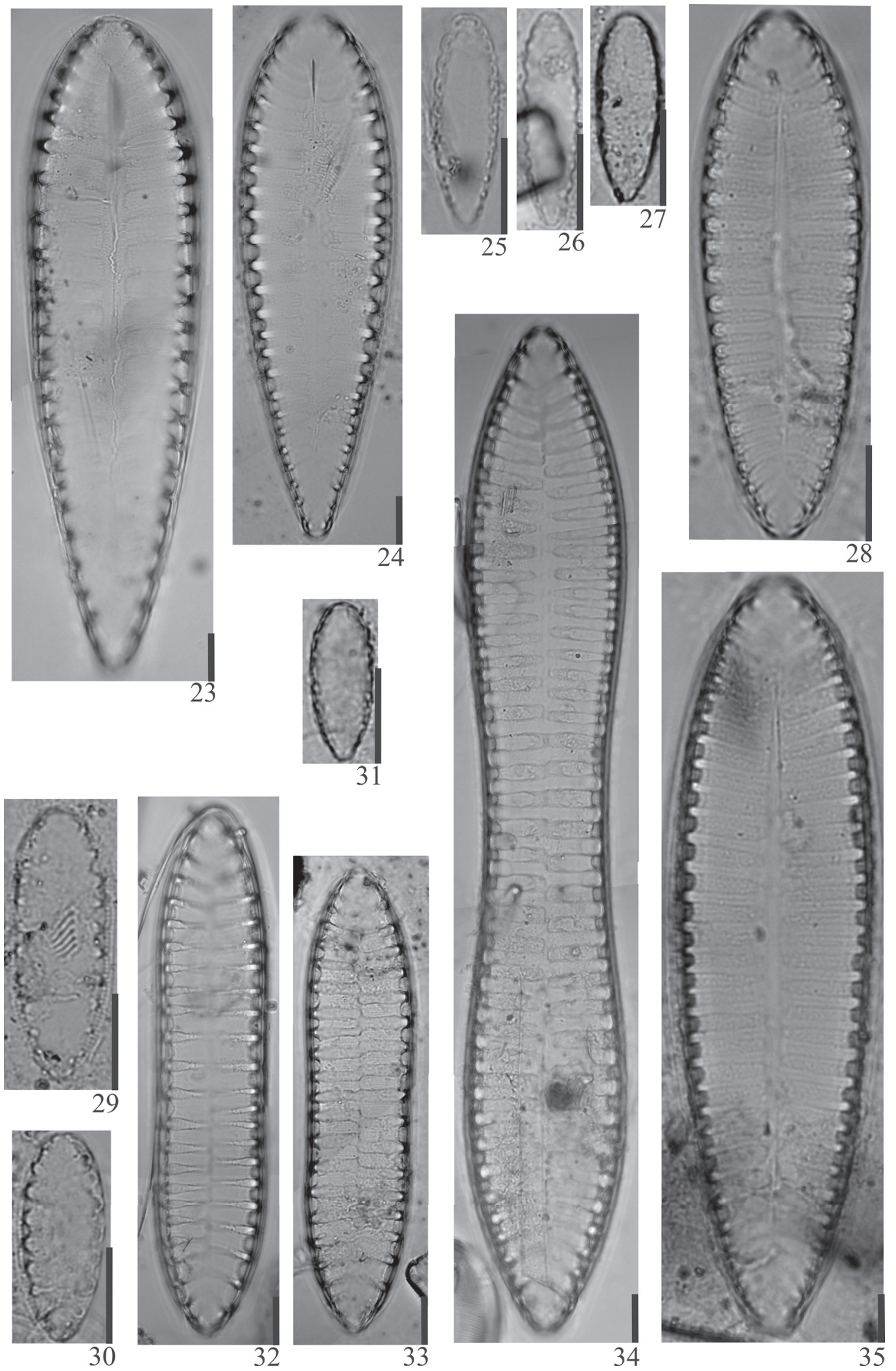

Figuras 23-35. Representantes de Surirellales. 23-24. Surirella tenera W. Gregory. 25-27. Surirella sp. 1. 28. Surirella sp. 2. 29-30. Surirella sp. 4. 31. Surirella sp. 3. 32-33. Surirella sp. 6. 34. Surirella sp. 7. 35. Surirella sp. 5. Barra de escala $=10 \mu \mathrm{m}$.

Figures 23-35. Surirellales representatives. 23-24. Surirella tenera W. Gregory. 25-27. Surirella sp. 1. 28. Surirella sp. 2. 29-30. Surirella sp. 4. 31. Surirella sp. 3. 32-33. Surirella sp. 6. 34. Surirella sp. 7. 35. Surirella sp. 5. Scale bar $=10 \mu \mathrm{m}$. 
Valvas heteropolares, assimétricas, espatuladas, extremidade apical arredondada, extremidade basal cuneada, área axial hialina, canais alares paralelos, costelas e fíbulas ausentes, quilha baixa, estrias não visíveis; 19,3-22,9 $\mu \mathrm{m}$ compr., 5,4-6,8 $\mu \mathrm{m}$ larg., Rc/1 3-4,1, 4-5 canais alares em $10 \mu \mathrm{m}$.

Hábitat: fitoplâncton e perifíton.

Material examinado: BRASIL. São Paulo: São Paulo, Parque Estadual das Fontes do Ipiranga, Centro de Ciência e Tecnologia, lago, 15-I-1997, D.C. Bicudo \& L.L. Morandi (SP294906, SP294907); Jardim Botânico, córrego Pirarungáua, 18-VII-1991, D.C. Bicudo, T.A.V. Ludwig \& D.M. Figueiredo (SP255749).

As populações presentemente estudadas lembram as de Surirella stalagma M.H. Hohn \& J. Hellerman (1963) pela heteropolaridade valvar e pelo tamanho dos espécimes. Contudo, S. stalagma possui a extremidade basal capitada e dimensões do comprimento $(13-14 \mu \mathrm{m})$ e da largura $(6,2 \mu \mathrm{m})$ valvares significativamente menores do que as respectivas dos espécimes ora em pauta.

Os indivíduos de Surirella tenuissima F. Hustedt (1937) ilustrados em Simonsen (1987) lembram os atuais do PEFI devido à heteropolaridade valvar, extremidades apical arredondada e basal cuneada, mas diferem pela presença de uma área axial levemente ondulada e pelas fíbulas paralelas entre si que se estendem até à área central.

Surirella margaritacea O. Müller (1903) ilustrada e descrita em Cocquyt \& Jahn (2005) apresentam características que lembram os exemplares do PEFI pela a heteropolaridade valvar e pelos canais alares arredondados nas extremidades. No entanto, o exemplar em Cocquyt \& Jahn (2005) possui medidas (compr. 44-45 $\mu \mathrm{m}$, larg. 21-26 $\mu \mathrm{m}$ ) maiores do que os presentes indivíduos do PEFI. Outra diferença está no formato valvar obovado e no esterno delimitado do material da África em Cocquyt \& Jahn (2005).

Em literatura, não foram observadas formas semelhantes às presentes do PEFI, o que nos levou a optar por identificar os atuais espécimes do PEFI como Surirella sp. 1.

No presente estudo, o exemplar ocorreu em 10,7\% das amostras analisadas de ambientes de condições oligotróficas.

\section{Surirella sp. 2}

Figuras 28
Valvas isopolares, simétricas, isobilaterais, lineares, linear-lanceoladas a elípticas, extremidade valvar arredondada a levemente cuneada, área axial estreita, hialina, canais alares paralelos, costelas finas, paralelas, alcançando a área axial, fíbulas ausentes, quilha baixa, estrias não visíveis; 43,3-54,1 $\mu \mathrm{m}$ compr., 17,5-16,6 $\mu \mathrm{m}$ larg., Rc/1 2,6-3,2, 3-4 canais alares em $10 \mu \mathrm{m}, 4-5$ costelas em $10 \mu \mathrm{m}$.

Hábitat: perifíton.

Material examinado: BRASIL. São PaUlo: São Paulo, Parque Estadual das Fontes do Ipiranga, Jardim Botânico, Lago dos Bugios, 7-XI-1996, D.C. Bicudo \& L.L. Morandi (SP294901); hidrofitotério, 7-VI-2011, P.D.A. Silva, G.C. Marquadt, S.W. Ribeiro \& B. Pelegrini (SP427342), 7-XI-1996, D.C. Bicudo \& L.L. Morandi (SP2949030).

As populações ora examinadas assemelham-se às de Surirella elegans C.G.Ehrenberg (1841) por conta da presença de costelas delicadas, mas, são diferentes na forma das valvas, pois $S$. elegans possui valva lanceolada, enquanto os presentes espécimes têm valvas elípticas. As medidas dos eixos valvar e pervalvar também diferem, sendo maiores em $S$. elegans (eixo valvar $129 \mu \mathrm{m}$, eixo pervalvar $60 \mu \mathrm{m}$ ).

A ultraestrutura da valva não foi observada ao MEV. Também não foram encontrados espécimes em literatura similares aos presentes do Lago dos Bugios e do hidrofitotério. Consequentemente, optou-se por identificar provisoriamente o material analisado como Surirella sp. 2 até que mais informação seja obtida sobre o material do PEFI.

No presente estudo, o exemplar ocorreu em 10,7\% das amostras analisadas de ambientes com condições mesotróficas.

\section{Surirella sp. 3}

Figura 31

Valvas heteropolares, assimétricas, espatuladas, extremidade apical arredondada, extremidade basal cuneada a arredondada, área axial hialina, canais alares curtos, paralelos, costelas e fíbulas ausentes, quilha baixa, estrias não visíveis ao microscópio óptico; ca. $16,3 \mu \mathrm{m}$ compr., ca. $6,5 \mu \mathrm{m}$ larg., Rc/1 ca. 2,5 , ca. 5 canais alares em $10 \mu \mathrm{m}$.

Hábitat: perifíton.

Material examinado: BRASIL. São Paulo: São Paulo, Parque Estadual das Fontes do Ipiranga, Jardim Botânico, córrego Pirarungáua, 18-VII-1991, 
D.C. Bicudo, T.A.V. Ludwig \& D.M. Figueiredo (SP255749).

O presente único exemplar deste tipo coletado do córrego Pirarungáua possui valvas heteropolares e medidas do comprimento e da largura valvares menores do que é usualmente referido na literatura. Tal espécime lembra representantes de Surirella stalagma M.H. Hohn \& J. Hellerman (1963), entretanto, os últimos possuem eixos valvar e pervalvar menores, extremidade basal capitada e fíbulas menos marcadas.

O espécime do PEFI também concordou morfologicamente com Surirella atomus F. Hustedt (1955) ilustrada em Simonsen (1987), no entanto, a última é distinta pelo formato valvar elíptico e pela posse de canais alares distintos e relativamente maiores. Outra diferença reside nas menores dimensões do comprimento e da largura valvares, que em $S$. atomus são: eixo valvar ca. $8,2 \mu \mathrm{m}$ e eixo pervalvar 5-8 $\mu \mathrm{m}$.

Apesar de apresentar valvas heteropolares e canais alares arredondados nas extremidades semelhantes aos de Surirella margaritacea O. Müller (1903) descrita e ilustrada por Cocquyt \& Jahn (2005), o único exemplar presentemente estudado difere pelo menor valor dos eixos apical e transapical (S. margaritacea: compr. 44-55 $\mu \mathrm{m}$, larg. 21-26 $\mu \mathrm{m}$ ) e pelo esterno não delimitado.

Não dispondo de muitas características em sua face valvar e devido à ausência de informação ultraestrutural, optou-se por identificar o único espécime ora coletado provisoriamente como Surirella sp. 3.

No presente estudo, o exemplar ocorreu em 3,5\% das amostras analisadas derivadas de ambientes com condições oligotróficas.

\section{Surirella sp. 4}

Figura 29-30

Valvas isopolares, simétricas, lineares a elípticas, extremidades arredondadas, área axial hialina, canais alares curtos, paralelos, arredondados, não ultrapassando as margens, costelas e fíbulas ausentes, quilha baixa, estrias não visíveis ao microscópio óptico; 21,1-27,6 $\mu \mathrm{m}$ compr., 9,4-12,1 $\mu \mathrm{m}$ larg., Rc/1 1,7-2,9, 3-4 canais alares em $10 \mu \mathrm{m}$.

Habitat: fitoplâncton.

Material examinado: BRASIL. São PaUlo: São Paulo, Parque Estadual das Fontes do Ipiranga, Centro de Ciência e Tecnologia, lago, 15-I-1997, D.C. Bicudo \& L.L. Morandi (SP294907).
Os dois únicos exemplares deste tipo atualmente examinados possuem características bastante peculiares em face valvar, ou seja, os canais alares são bem marcados e não alcançam a área central da valva. Suas extremidades são fortemente arredondadas e não ocorre ornamentação na face valvar.

Surirella margaritacea O. Müller (1903) descrita e ilustrada por Cocquyt \& Jahn (2005) lembra os indivíduos encontrados no PEFI pelos canais alares arredondados nas extremidades. Contudo, difere, pelos maiores valores de comprimento e largura (compr. 44-55 $\mu \mathrm{m}$, larg. 21-26 $\mu \mathrm{m}$ ) e pela área central fortemente delimitada.

Não foi possível analisar ultraestruturalmente a frústula dos dois espécimes presentemente estudados, bem como não há na literatura espécimes que possam ser comparados com os atuais do PEFI. Nestas condições, optou-se por identificá-los como Surirella sp. 4.

No presente estudo, o exemplar ocorreu em 3,5\% das amostras analisadas provenientes de ambiente com condição oligotrófica.

\section{Surirella sp. 5}

Figura 35

Valvas heteropolares, assimétricas, lineares a linear-lanceoladas, extremidades apical arredondada a levemente cuneada, extremidade basal cuneada, área axial hialina, alcançando as extremidades, canais alares curtos, paralelos, costelas paralelas, finas, fíbulas ausentes, quilha baixa, estrias não visíveis ao microscópio óptico; ca. 79,3 $\mu \mathrm{m}$ compr., ca. 23,2 $\mu \mathrm{m}$ larg., Rc/1 ca. 3,4, ca. 4 canais alares em $10 \mu \mathrm{m}$, ca. 4 costelas em $10 \mu \mathrm{m}$.

Habitat: perifíton.

Material examinado: BRASIL. São PAULO: São Paulo, Parque Estadual das Fontes do Ipiranga, Jardim Botânico, Lago dos Bugios, 7-XI-1996, D.C. Bicudo \& L.L. Morandi (SP294901).

O único exemplar coletado no PEFI lembra os representantes do grupo robustóide do gênero.

Representantes de Surirella tenera W. Gregory (1856) podem ser comparados ao presente do PEFI pela heteropolaridade valvar, extremidade apical arredondada e extremidade basal ligeiramente cuneada, no entanto, os últimos não apresentam espinhos em qualquer dos ápices. Devido à ausência de espinhos e por não haver informação morfológica suficiente para identificar o único exemplar em pauta 
como representante de uma determinada espécie, optou-se por identificá-lo como Surirella sp. 5.

No presente estudo, o exemplar ocorreu em 3,5\% das amostras coletadas de ambientes com condições mesotróficas.

\section{Surirella sp. 6}

Figuras 32-33

Valvas isopolares, simétricas, lineares a linearlanceoladas, extremidades arredondadas a levemente cuneadas, área axial estreita, hialina, alcançando as extremidades, canais alares curtos, paralelos, costelas paralelas, robustas, fíbulas ausentes, quilha alta, estrias não visíveis ao microscópio óptico; 96,1-109 $\mu \mathrm{m}$ compr., 21,3-21,9 $\mu \mathrm{m}$ larg., Rc/1 4,5-5, 2-3 canais alares em $10 \mu \mathrm{m}$, ca. 3 costelas em $10 \mu \mathrm{m}$.

Hábitat: perifiton/metafíton.

Material examinado: BRASIL. São PAUlo: São Paulo, Parque Estadual das Fontes do Ipiranga, Centro de Ciência e Tecnologia, brejo do lago, 15-I-1997, D.C. Bicudo \& L.L. Morandi (SP294908).

Os presentes exemplares do brejo do lago do Centro de Ciência e Tecnologia possuem características semelhantes às de duas espécies em Simonsen (1987), quais sejam: Surirella aculeata F. Hustedt e Surirella elgeri F. Hustedt. Os representantes destas duas espécies são característicos por possuírem valvas isopolares, nítida a levemente constritas na parte média e ápices arredondados a levemente arredondados. Contudo, ambas as espécies possuem pequenas papilas (porcas) na face valvar que em $S$. aculeata alcançam toda a face valvar e em S. elgeri limitam-se às extremidades, características estas não observadas no atual material do PEFI.

Não existe informação ultraestrutural sobre o presente material do PEFI que possibilite a visualização da presença de porcas, como foi o caso das duas espécies acima. É valido ressaltar que as características morfológicas ora observadas são incomuns na literatura sobre Surirella. É nossa posição que mais exemplares devam ser examinados para concluir sobre a identificação taxonômica do presente material.

No presente estudo, o exemplar ocorreu em 3,5\% das amostras analisadas provenientes de condições oligotróficas.

\section{Surirella sp. 7}

Figura 34

Valvas isopolares, simétricas, isobilaterais, extremidades fortemente cuneadas, área axial hialina, estreita, alcançando as extremidades, canais alares paralelos entre si, costelas robustas, paralelas, radiadas nos ápices, fíbulas ausentes, quilha elevada, estrias não visíveis; ca. $209 \mu \mathrm{m}$ compr., ca. 33,5 $\mu \mathrm{m}$ larg., Rc/1 ca. 6,2 , ca. 2 canais alares em $10 \mu \mathrm{m}$, ca. 2 costelas em $10 \mu \mathrm{m}$.

Hábitat: perifíton/metafíton.

Material examinado: BRASIL. São PAUlo: São Paulo, Parque Estadual das Fontes do Ipiranga, Centro de Ciência e Tecnologia, brejo do lago, 15-I-1997, D.C. Bicudo \& L.L. Morandi (SP294908).

O único exemplar atualmente examinado lembra os representantes de Surirella linearis W. Smith var. constricta A. Grunow devido à isopolaridade valvar, à existência de constrição mediana e à área central hialina e estreita, no entanto, o material ilustrado em Lange-Bertalot (2005) é bem menor tanto no comprimento do eixo valvar $(29-43 \mu \mathrm{m})$ quanto no pervalvar $(9-11 \mu \mathrm{m})$.

Representantes de duas outras espécies (Surirella grandifera F. Hustedt e Surirella thienemannii F. Hustedt) ilustradas em Simonsen (1987) lembram o atualmente encontrado. A primeira difere por possuir uma forte constrição central e extremidades cuneadas, além de apresentar costelas alternadas na região mediana. A segunda difere por possuir a área axial hialina maior e bem marcada e ápices valvares apiculados.

O presente exemplar de Surirella sp. 7 mostra características mais próximas daquelas de Surirella africani-orientalis Cocquyt \& Jahn ilustrada em Cocquyt \& Jahn (2005) graças aos valores do comprimento e da largura (S. africani-orientalis: compr. 135-413 $\mu \mathrm{m}$, larg. 30-50 $\mu \mathrm{m}$ ), margem fortemente constrita no meio e à "pseudo rafe" distinta em uma linha continua. No entanto, as populações ilustradas por Cocquyt \& Jahn (2005) possuem ápices valvares levemente cuneados a arredondados e costas que se divergem nas extremidades. Por haver encontrado apenas um exemplar deste tipo no presente estudo (necessitando de mais indivíduos para melhor comparação), optou-se por identificar o espécime do PEFI como representante de Surirella sp.7 até que um estudo mais detido com populações e a obtenção de fotomicrografias ao MEV sejam obtidas.

No presente estudo, o exemplar ocorreu em 3,5\% das amostras coletadas em condições oligotróficas.

\section{Considerações finais}

Quinze espécies pertencentes à família Surirellaceae e dois gêneros (Stenopterobia e Surirella) foram identificados, incluindo sete materiais em nível 
gênero por conta ora da escassez de espécimes (apenas um) ora da ausência de informação morfológica, ultraestrutural e/ou de literatura que pudesse auxiliar na identificação desses espécimes. Para o Parque Estadual das Fontes do Ipiranga, oito espécies foram citadas pioneiramente e são: Stenopterobia delicatissima (F.W. Lewis) L.A. Brébisson ex H. van Heurck, $S$. pelagica F. Hustedt, S. planctonica D. Metzeltin \& H. Lange-Bertalot, S. curvula (W. Smith) K. Kramer, Surirella angusta F.T. Kützing, S. guatimalensis C.G. Ehrenberg, S. stalagma M.H. Hohn \& J. Hellerman, $S$. splendida (C.G. Ehrenberg) F.T. Kützing e S. tenera W.Gregory. Além dos seguintes táxons Surirella sp. 1, Surirella sp. 2, Surirella sp. 3, Surirella sp. 4, Surirella sp. 5, Surirella sp. 6 e Surirella sp. 7.

O maior número de espécies (oito) foi identificado no Lago do Centro de Ciência e Tecnologia. Este lago é classificado oligotrófico (Bicudo et al. 2002) e é o mais protegido dos reservatórios do PEFI por conta da vegetação (Bicudo et al. 2002). Seis espécies foram identificadas para o hidrofitotério. O Lago das Ninfeias (mesotrófico) apresentou quatro espécies, foi seguido pelo córrego Pirarungáua com três espécies e pelos lagos dos Bugios e do Monjolo e pelo ambiente subaéreo (tronco de árvore e musgos) com duas espécies cada um.

Surirellales foram amplamente encontradas no perifíton (15 espécies), seguido do fitoplâncton (cinco espécies) e, por último, do epilíton e do metafíton, com duas espécies, respectivamente. Oito espécies foram restritas ao perifíton (Stenopterobia planctonica, Surirella splendida, S. stalagma, S. tenera, Surirella sp. 2, Surirella sp. 3, Surirella sp. 5, Surirella sp. 6 e Surirella sp. 7), duas foram exclusivas do fitoplâncton (Stenopterobia curvula e Surirella sp. 4) e apenas uma foi restrita ao epilíton de ambiente subaéreo (Surirella angusta).

Stenopterobia delicatissima e S. pelagica foram as espécies melhor distribuídas em termos espaciais, ou seja, S. pelagica ocorreu em quatro localidades: Lago das Ninfeias, hidrofitotério, Lago do Monjolo e material sobre musgos e tronco de árvore (ambiente subaéreo) e S. delicatissima em três (córrego Pirarungáua, Lago do Centro de Ciências e Tecnologia e hidrofitotério).

O número aparentemente elevado de materiais identificados apenas em nível gênero representado por sete prováveis espécies novas de Surirella deve-se a vários fatores, como segue: (1) apenas um espécime do tipo ter sido encontrado nas amostras estudadas; (2) a considerável escassez de literatura especializada observada em nível mundial; e (3) a falta de observação da maioria dos materiais ao microscópio eletrônico de varredura ora pela falta de espécimes nas preparações providenciadas, ora pela escassez de material nas amostras.

\section{Agradecimentos}

Os autores agradecem ao CNPq, Conselho Nacional de Desenvolvimento Científico e Tecnológico pela bolsa de Mestrado concedida a KSMF e de Pesquisa a CEMB; e aos dois revisores anônimos pelas contribuições.

\section{Literatura citada}

Adl, S.M., Simpson, A.C.B., Farmer, M.A., Andersen, R.A., Anderson, O.R., Barta, J.R., Bowser, S.S., Brugerolle, G., Fensome, R.A., Frederiq, S., James, T.Y., Karpov, S., Kugrens, P., Krug, J., Lane, C.E., Lewis, L.A., Lodge, J., Lynn, D.H., Mann, D.G., McCourt, R.M.; Mendonza, L.; Øjvind, M.; Mozley-Standridge, S.E., Nerad, T.A., Shearer, C.A., Smirnov, A.C., Spiegelz, F.W. \& Taylor, M.F.J.R. 2005. The new higher-level classification of Eukaryotes with emphasis on the taxonomy of protists. Journal of Eukaryotes Microbiology 52: 399-451.

Almeida, P.D. \& Bicudo, D.C. 2014. Diatomáceas planctônicas e de sedimento superficial em represas de abastecimento da Região Metropolitana de São Paulo, SP, Sudeste do Brasil. Hoehnea 41: 187-202.

Aprile, F.M. \& Mera, P.A.S. 2007. Fitoplâncton e Fitoperifíton de um rio de águas pretas da Amazônia Periférica do Norte, Brasil. Brazilian Journal of Aquatic Sciences and Technology 11:1-14.

Bartozek, E.C.R., Bueno, N.C., Ludwig, T.A.V., Tremarim, P.I., Nardelli, M.S. \& Rocha, A.C.R. 2013. Diatoms (Bacillariophyceae) of Iguaçu National Park, Foz do Iguaçu, Brazil. Acta Botanica Brasilica 27: 108-123.

Bess, D., Ector, L., Torgan, L.C. \& Lobo, E.A. 2012. Composition of the epilithic diatom flora from a subtropical river, Southern Brazil. Iheringia: Série Botânica 67: 93-125.

Bicudo, C.E.M., Carmo, C.F., Bicudo, D.C., Henry, R., Pião, A.C.S., Santos, C.M. \& Lopes, M.R.M. 2002. Morfologia e morfometria de três reservatórios do PEFI. In: D.C. Bicudo, M.C. Forti \& C.E.M. Bicudo (eds.). Parque Estadual das Fontes do Ipiranga: unidade de conservação que resiste à urbanização de São Paulo. Secretaria do Meio Ambiente do Estado de São Paulo, São Paulo.

Bicudo, C.E.M. \& Menezes, M. 2006. Gêneros de algas de águas continentais do Brasil: chave para identificação de gêneros. 2 ed. RiMa Editora, São Carlos. 
Bicudo, C.E.M., Morandi, L.L., Araújo, A., Carneiro, L.A. \& Bicudo, D.C. 2009. Algas. In: M.I.M.S. Lopes, M. Kirizawa, \& M.M.R.F. Melo, (eds.). Patrimônio da Reserva Biológica do Alto da Serra de Paranapiacaba: a antiga Estação Biológica do Alto da Serra. Instituto de Botânica, São Paulo. pp. 185-212.

Bicudo, D.C., Forti, M.R., Carmo, C.F., Bourotte, C., Bicudo, C.E.M., Melfi, A.J. \& Lucas, Y. 2002. A Atmosfera, as águas superficiais e os reservatórios no PEFI: caracterização química. In: D.C. Bicudo, M.C. Forti \& C.E.M. Bicudo (eds.). Parque Estadual das Fontes do Ipiranga: unidade de conservação que resiste à urbanização de São Paulo. Secretaria do Meio Ambiente do Estado de São Paulo, São Paulo.

Bramburguer, A.J., Hamilton, P.B., Hinz, F. \& Hehanussa, P.E. 2006. An examination of species within the genus Surirella from the Malili Lakes, Sulawesi Island, Indonesia, with descriptions of 11 new taxa. Diatom Research 21: 1-56.

Brun, J. 1880. Diatomées des Alpes et du Jura et de la region Suisse et Française des environs de Gèneve. Imprimerie Ch. Schuchardt, Gèneve.

Burliga, A.L., Torgan, L.C., Nobrega, E.A., Beaumord, A.C., Costa, C.O. \& Yamauti, D.V. 2005. Diatomáceas epilíticas do rio Itajaí-Mirim, Santa Catarina, Brasil. Acta Scientiarum: Biological Sciences 4: 415-421.

Cocquyt, C. \& Jahn, R. 2007. Surirella engleri O.Müller: a study of its original infraespecific types, variability and distribution. Diatom Research 22: 1-16.

Cocquyt, C., Jüttner, I. \& Kusber, W.H. 2013. Reivestigation of West African Surirellaceae (Bacillariophyta) described by Woodhead and Tweed from Sierra Leone. Diatom Research 28: 121-129.

Cocquyt, C. \& Taylor, J.C. 2015. New and interesting Surirella taxa (Surirellaceae, Bacillariophyta) from the Congo Basin (DR Congo). European Journal of Taxonomy 133: 1-15.

Cocquyt, C., Taylor, J.C. \& Wetzel, C.E. 2014. Stenopterobia caractarum sp. nov. (Bacillariophyta), a new benthic diatom from a waterfall in Zambia, Africa. Phytotaxa 158: 76-84.

Costa, S.V. 2008. Histórico de eutrofização do Lago das Garças (Parque Estadual das Fontes do Ipiranga, São Paulo) durante o século XX com base no registro das diatomáceas em sedimentos. Tese de Doutorado, Instituto de Botânica, Secretaria do Meio Ambiente do Estado de São Paulo, São Paulo.

Ehrenberg, C.G. 1841. Characteristik von 274 neuen Arten von Infusorien. Bericht über die zur Bekanntmachung geeigneten Verhandlungen der Königlich-Preussischen Akademie der Wissenschaften zu Berlin, Berlin.

English, J. 2011. Surirella minuta. In: Diatoms of the United States. Disponível em http://westerndiatoms. colorado.edu/taxa/species/surirella_minuta (acesso em 24-IX-2016).
Eskinazi-Leça, E., Moura, C.W.N., Cunha, M.G.G.S., Santiago, M.F., Borges, G.C.P., Lima, J.C., Silva, M.H., Ferreira, L.C., Aquino, E., da Silva, W.J. \& Menezes, M. 2015. Bacillariophyceae in Lista de Espécies da Flora do Brasil. Jardim Botânico do Rio de Janeiro. Disponivel em http://floradobrasil.jbrj.gov.br/ jabot/floradobrasil/FB119448 (acesso em 29-IX-2016)

Fernandes, A.J., Reis, L.A.M. \& Carvalho, A. 2002. Caracterização do Meio Físico In: D.C. Bicudo, M.C. Forti \& C.E.M. Bicudo (eds.). Parque Estadual das Fontes do Ipiranga: unidade de conservação que resiste à urbanização de São Paulo. Secretaria do Meio Ambiente do Estado de São Paulo, São Paulo.

Ferragut, C. 2004. Respostas de algas perifíticas e bentônicas à manipulação de nutrientes $(\mathrm{N}$ e $\mathrm{P})$ em reservatório urbano (Lago do IAG, São Paulo). Tese de Doutorado. Universidade Estadual Paulista, Rio Claro.

Flôres, T.L., Moreira-Filho, H. \& Ludwig, T.A.V. 1999. Contribuição ao inventário florístico das diatomáceas (Bacillariophyta) do Banhado do Taim, Rio Grande do Sul, Brasil, 1: Epithemia Brébisson ex Kützing. Rophalodia O. Müller e Surirella Turpin. Insula 28: 149-166.

Fonseca, B.M., Ferragut, C., Tucci, A., Crossetti, L.O., Ferrari, F., Bicudo, D.C., Sant'Anna, C.L.\& Bicudo, C.E.M. 2014. Biovolume de cianobactérias e algas de reservatórios tropicais do Brasil com diferentes estudos tróficos. Hoehnea 41: 9-30.

Fourtanier, E. \& Kociolek, J.P. 2011 . Catalogue of Diatom Names. California Academy of Sciences. Disponível em http://research.calacademy.org/ research/diatoms/ names/index.asp (acesso em 01-X-2016).

Fürstenberger, C.B. \& Valente-Moreira, I.M. 2000. Diatomáceas (Bacillariophyta) perifíticas da Lagoa do Tarumã, Ponta Grossa, Paraná, Brasil, 1: Bacillariphycidae (exceto Eunotiaceae). Insula 29: 25-65.

Gasse, F. 1986. East African diatoms: taxonomy, ecological distribution. J. Cramer, Berlin.

Germain, H. 1981. Flore de Diatomées. Societé Nouvelle des Éditions Boubée, Paris.

Graça, S., Garcia, M.J. \& Oliveira, P.E. 2007. Flora diatomácea moderna do Lago da Estância das Águas Claras, Guarulhos (SP), resultados qualitativos. UnG, Geociências 6: 63-78.

Gregory, W. 1856. Notice of some new species of British fresh-water Diatomaceae. Quarterly Journal of Microscopical Science, new series 4: 1-14.

Hermany, G., Schwarbold, LD., Lobo, E.A. \& Oliveira, M.A. 2000. Ecology of the epilithic diatom community in a low-order stream system of the Guaíba hydrographical region: subsidies to the environmental monitoring of southern Brazilian aquatic systems. Acta Limnologica Brasiliensia 18: 9-27.

Hustedt, F. 1937. Systematische und ökologische Untersuchungen über die Diatomeen-Flora von Java, Bali und Sumatra nach dem Material der Deutschen Limnologischen Sunda-Expedition. Archiv für Hydrobiologie (Supplement) 15: 178-295. 
Hustedt, F. 1965. Neue und wenig bekannte Diatomée, 9: Süßwasserdiatomeen aus Brasilien insbesondere des Amazonasgebietes. Internationale Revue der Gesamten hydrobiologie und Hydrographie 50: 391-410.

Hustedt, F. 1985. The Pennate Diatoms (a translation of Hustedt's “Die Kieselalgen, 2 Teil” by Norma Jensen). Koeltz Scientific Books, Koenigstein.

Krammer, K. 1989. Functional valve morphology in some Surirella species (Bacillariophyceae) and comparison with the Naviculaceae. Journal of Phycology 25: 159-167.

Kramer, K. \& Lange-Bertalot, H. 1988. Süßwasserflora von Mitteleuropa, 2: Bacillariaceae, Epithemiaceae, Surirellaceae. Gustav Fischer, Stuttgart.

Kützing, F.T. 1844. Die kieselschaligen Bacillarien Oder Diatomeen. Nordhausen.

Kützing, F.T. 1849. Species algarum. F.A. Brockhaus, Lipsiae [Leipzig].

Laux, M. \& Torgan L.C. 2011. Diatomáceas com plastídeos no plâncton da foz dos rios do Delta do Jacuí, sul do Brasil: um complemento à taxonomia tradicional. Iheringia: Série Botânica 66: 109-132.

Lopes, M.R.M. 1999. Eventos pertubatórios que afetam a biomassa, a composição e a diversidade de espécies do fitoplâncton em um lago tropical oligotrófico raso (Lago do Instituto Astronômico e Geofísico, São Paulo, SP). Tese de Doutorado. Universidade de São Paulo, São Paulo.

Lowe, R.L. 2003. Keeled and canalled raphid diatoms. In: J.D. Wehr \& R.G. Sheath (eds.). Freshwater Algae of North America: ecology and classification. Academic Press, San Diego, pp. 669-684.

Marquardt, G.C. \& Bicudo, C.E.M. 2014. Criptógamos do Parque Estadual das Fontes do Ipiranga, São Paulo, SP. Algas 36: Bacillariophyceae (Cymbellales). Hoehnea 41: 209-246.

Medlin, L.K. \& Kaczmarska, I. 2004. Evolution of diatoms, 5: morphological and cytological support for the major clade and a taxonomy revision. Phycologia 43: $245-270$.

Menezes, M. 2015. Update of the Brazilian floristic list of Algae and Cyanobacteria. Rodriguesia 66: 1047-1062.

Metzeltin, D. \& Lange-Bertalot, H. 1998. Tropical Diatoms of South America. In: H. Lange-Bertalot (ed.). Iconografia Diatomologica: annotated diatom micrographs. Koeltz Scientific Books, Suttgart. v. 5.

Metzeltin, D., Lange-Bertalot, H. \& García-Rodríguez. 2005. Diatoms of Uruguay. In: H. Lange-Bertalot (ed.). Iconografia Diatomologica: annoted diatom micrographs. A.R.G. Gantner Verlag Kommanditgesellschaft, Königstein. v. 15.

Moreira-Filho, H. \& Valente-Moreira, I.M. 1981. Avaliação taxonômica e ecológica das diatomáceas (Bacillariophyceae) epifíticas em algas pluricelulares obtidas dos litorais do Estado do Paraná, Santa Catarina e São Paulo. Boletim do Museu Botânico Municipal 47: 1-17.
Moutinho, S.O., Garcia, M.J. \& Oliveira, P.E. 2007. Flora diatomácea do Reservatório Cabuçu, Município de Guarulhos, (SP): Análise quantitativa. Revista UnGGeociências 6: 32-62.

Nastri, V.D.F., Catharino, E.L.M., Rossi, L., Barbosa, L.M., Pirré, E., Bedinelli, C., Asperti, L.M., Dorta, R.O. \& Costa, M.P. 1992. Estudos fitossociológicos em uma área do Instituto de Botânica de São Paulo utilizados em programas de educação ambiental. Anais do $2^{\circ}$ Congresso Nacional sobre Essências Nativas. Revista do Instituto Florestal 4: 219-225.

Oliveira, B.D., Nogueira, I.S. \& Souza, M.G.M. 2012. Stenopterobia e Surirella (Bacillariophyceae, Surirellaceae) do Sistema Lago dos Tigres, Britânia, Goiás. Rodriguesia 63: 525-539.

Oliveira, M.A., Torgan, L.C., Lobo, E.A \& Scharzbold, A. 2001. Association of periphytic diatom species of artificial substrate in lotic environments in the Arroio Sampaio basin, RS, Brazil: relationships with abiotic variables. Brazilian Journal of Biology 61: 523-54.

Rabenhorst, L. 1853. Die Süsswasser-Diatomaceen (Bacillarien.): für Freunde der Mikroskopie. Eduard Kummer, Leipzig.

Rivera, P.R. 1974. Diatomeas de agua dulce de Concepción y alrededores (Chile). Gayana 28: 3-134.

Rocha, A.C.R. \& Bicudo, C.E.M. 2008. Criptógamos do Parque Estadual das Fontes do Ipiranga, São Paulo, SP. Algas, 25: Bacillariophyceae (Naviculales: Pinnulariaceae). Hoehnea 35: 597-618.

Round, F.E., Crawford, R.M. \& Mann, D.G.1990. The diatoms: biology and morphology of the genera. Cambridge University Press, Cambridge.

Ruck, E.C. 2010. Phylogenetic systematics of the canal raphe bearing orders Surirellales and Rhopalodiales (Bacillariophyta). Doctoral Dissertation. University of Texas at Austin, Texas.

Ruck, E.C.\& Theriot, E.C. 2011. Original and evolution of the canal raphe system in diatoms. Protist 162: 1-15.

Sala, S.E., Ramírez, J.J., Vouilloud, A.A. \& Plata-Díaz, Y. 2013. Surirella antioquiensis sp. nov. and S. rafaelii sp. nov. (Bacillariophyta) from Colombia. Acta Nova 6: 17-35.

Salomoni, S.E. \& Torgan, L.C. 2010. O gênero Surirella Turpin (Surirellaceae, Bacillariophyta) em ambientes aquáticos do Parque Estadual Delta do Jacuí, sul do Brasil. Iheringia: Série Botânica 65: 281-290.

Santos, E.M., Tremarin, P.I. \& Ludwig, T.A.V. 2011. Diatomáceas perifíticas em Potamogeton polygonus Cham. \& Schltdl.: citações pioneiras para o estado do Paraná. Biota Neotropica 11: 304-315.

Santos, P.M. \& Funari, F.L. 2002. Clima Local. In: Parque Estadual das Fontes do Ipiranga. Secretaria do Meio Ambiente do Estado de São Paulo, São Paulo, pp. 31-46.

São Paulo. 1991. Vegetação significativa do município de São Paulo. Secretaria do Meio Ambiente do Estado de São Paulo, São Paulo. 
Schmidt, A. 1874-1959. Atlas der Diatomaceen-Kunde. R. Reisland, Leipzig.

Shirata, M.T. \& Valente-Moreira, I.M.1987. Ocorrência das diatomáceas Attheya zachariasi e Surirella stalagma no lago do parque São Lourenço, Curitiba, PR, Brasil. Acta Biologica Paranaense 16: 87-92.

Silva, A.M., Ludwig, T.A.V., Tremarim, P.I. \& Vercellino, I.S. 2010. Diatomáceas perifíticas em um sistema eutrófico brasileiro (Reservatório do Iraí, estado do Paraná). Acta Botanica Brasilica 24: 997-1016.

Simonsen, R. 1987. Atlas and catalogue of diatom types of Friederich Hustedt. J. Cramer, Berlin.

Siver, P.A. \& Camfield, L. 2007. Studies on the diatoms genus Stenopterobia (Bacillariophyceae) including descriptions of two new species. Canadian Journal of Botany 85: 822-849.

Siver, P.A. \& Hamilton, P.B. 2005. Observations on new and rare species of freshwater diatoms from Cape Cod, Massachusetts, EUA. Canadian Journal of Botany 83: 362-378.

Siver, P.A., Hamilton, P.B., Stachura-Suchoples, K. \& Kociolek, P. 2005. Diatoms of North America: the freshwater flora of Cape Cod, Massachusetts, U.S.A. In: H. Lange-Bertalot (ed.). Iconografia Diatomologica: annotated diatom micrographs. A.R.G. Gantner Verlag Kommanditgesellschaft, Königstein.
Souza-Mosimman, R.M., Silva, R.L. \& Roos-Oliveira, A.M. 2001. Diatomáceas (Bacillariophyta) da Baia Sul, Florianópolis, Santa Catarina, Brasil, uma nova contribuição. Insula 30: 75-106.

Steverson, R.J., Bothwell, M.X. \& Lowe, R.L. 1996. Algal ecology: freshwater benthic ecosystems. Academic Press, New York.

Teixeira, C. \& Kutner, M.B. 1960. Contribuição para o conhecimento das diatomáceas da região de Cananéia. Boletim do Instituto Oceanográfico 151: 41-72.

Torgan, L.C. \& Weber, A.S. 2008. Novos registros de Surirella Turpin (Bacillariophyta, Surirellaceae) para o Rio Grande do Sul e Brasil. Acta Botanica Brasilica 22: 393-398

Turpin, P.J.F. 1827. Observations sur le nouveu genre Surirella. Memórie du Museum 16: 47-368.

van Heurck, H. 1880. Synopsis des Diatomées de Belgique. Atlas. Ducaju et Cie, Anvers.

van Heurck, H. 1885. Synopsis des diatomées de Belgique. M. Brouner, private published, Anvers. Texte.

Veloso, H.P. \& Goés-Filho, L. 1982. Fitogeografia Brasileira. Salvador: Ministério das Minas e Energia, Projeto RADAMBRASIL.

Vyvermann, W. 1991. Diatoms from Papua New Guinea. Bibliotheca Diatomologia 22: 1-225. 